\title{
CONTROLE ALTERNATIVO DE CUPINS DO GÊNERO Nasutitermes sp. COM USO DE EXTRATOS E ÓLEOS VEGETAIS DE Lippia thymoides E Lippia lausocalycina, EM FEIRA DE SANTANA, BAHIA, BRASIL.
}

\author{
Iara Liandra Santana Silva ${ }^{1}$; Jucelho Dantas da $\mathrm{Cruz}^{2}$; Daiane Rodrigues dos $\operatorname{Santos}^{3}$ e \\ Mainã Medeiros Oliveira ${ }^{4}$ \\ 1. Bolsista PIBIC/CNPq, Graduando em agronomia, Universidade Estadual de Feira de Santana, e-mail: \\ yara_lian@hotmail.com \\ 2. Orientador, Departamento de ciências biológicas, Universidade Estadual de Feira de Santana, e-mail: jucelho@ig.com.br \\ 3. Participante do projeto ou núcleo tal, Departamento de ciências biológicas, Universidade Estadual de Feira de Santana, e- \\ mail: daibio@hotmail.com.br \\ 4. Participante do projeto ou núcleo tal, Departamento de ciências biológicas, Universidade Estadual de Feira de Santana, e- \\ mail: maina_medeiros@hotmail.com
}

PALAVRAS-CHAVE: Lippia sp; Nasutitermes sp; Biopesticida.

\section{INTRODUÇÃO}

O semi-árido nordestino desponta como um dos ecossistemas mais valiosos, apresentando em seu domínio um número expressivo de espécies vegetais endêmicas, como planta xerófilas de fisionomia e florística variada, com elevado potencial para produção de substâncias bioativas (QUEIROZ et al. 2006; GIULIETTI et al. 2004). E dentre a grande riqueza florística com potencial, podemos citar o gênero Lippia, que é um dos mais importantes representantes da família (Verbenaceae), com 200 espécies de ervas, arbustos e pequenas árvores. No Brasil, este gênero pode ser encontrado nos estados de Minas Gerais e Bahia, com a maioria das espécies distribuídas nos biomas Cerrado e Caatinga (OLIVEIRA et al. 2007; GOMES et al. 2011).

Os cupins do gênero Nasutitermes sp. (Termitidae), conhecidos como cupins arborícolas são considerados as principais pragas que causam danos econômicos ao homem. O uso do tratamento químico contra esses insetos, apesar de eficiente é altamente tóxico para os seres vivos e ocasiona contaminação ambiental (ROMAGNANO \& NAHUZ, 2006). Com isso, o controle realizado por extratos vegetais e óleos essenciais vem sendo cada vez mais estudado porem, o escasso numero de informações sobre o potencial bioinseticida das espécies endêmicas do semiárido, sobretudo das espécies de Lippia, motivaram o presente estudo que teve como objetivo avaliar o potencial inseticida de Lippia. thymoides e Lippia lasiocalycina, contra cupins do gênero Nasutitermes sp e determinar a entomofauna associada às espécies vegetais.

\section{METODOLOGIA}

Para obtenção do extrato metanólico bruto, aproximadamente $300 \mathrm{~g}$ de folhas de cada espécie foram submetidas a seis extrações com metanol por 72 horas e concentradas em um rota evaporador. A obtenção do extrato aquoso foi realizada por meio da maceração das folhas no almofariz, que foram misturadas à água destilada. O método utilizado para extração do óleo foi o de arraste a vapor, sendo empregado o aparelho de destilação tipo Clevenger. Após a obtenção dos extratos e óleo vegetais, os insetos foram submetidos à avaliação do potencial inseticida in vitro, utilizando as concentrações iniciais de $1 \%$ dos óleos, $10 \%$ do extrato aquoso e $100 \mathrm{mg} \cdot \mathrm{ml}^{-1}$ do extrato metanólico bruto, através da metodologia adaptada empregada por SANTOS et al. (2010).

Na determinação da Concentração Letal (CL50) e Tempo Letal (TL50) apenas o(s) extrato(s) ou óleos que expressaram atividade inseticida no teste anterior, foram fracionados em diferentes concentrações para seleção da dose mínima com potencial inseticida. Os óleos foram diluídos em oito concentrações: $10,5,2.5,1.25,0.625,0.3125,0.15625 \mu 1 . \mathrm{ml}^{-1}$ e a 
solução de tween $1 \%$ (controle). O experimento executado foi semelhante ao bioensaio anterior, no qual a mortalidade dos insetos foi avaliada durante as seis primeiras horas, $24 \mathrm{e}$ 48 horas após a aplicação.

Para avaliação dos mecanismos de ação foram testados três diferentes mecanismos com a Concentração Letal (CL50) determinada pelo teste anterior. No teste de exposição por aplicação tópica dez insetos foram postos em placas de Petri com as mesmas especificações anterior contendo fragmentos do ninho borrifados com $2 \mathrm{ml}$ das soluções com óleo essencial na concentração de $10 \mu \mathrm{l} \cdot \mathrm{ml}^{-1}$ e da solução de tween $1 \%$ (controle) por placa. Na exposição por superfície contaminada foram utilizadas as mesmas soluções do bioensaio com aplicação tópica, colocando-se $1,5 \mathrm{ml}$ de cada solução por placa de Petri com lotes de dez insetos e pequenos pedaços do seu ninho. Ambos os testes foram executados em delineamento inteiramente casualizado com dez repetições por tratamento. A mortalidade dos insetos foi avaliada 24 e 48 horas após a aplicação e a eficiência dos tratamentos foi determinada através da análise de variância e as médias comparadas pelo teste de Tukey a 5\% de probabilidade.

Para os testes de repelência, pequenos pedaços de madeira foram imersos em solução de $10 \mu \mathrm{l} . \mathrm{ml}^{-1}$ do óleo essencial e em solução de tween $1 \%$ (controle). No interior das placas de Petri de 9,0 cm de diâmetro foi posicionado papel filtro demarcado com uma linha central, sendo colocados pequenos pedaços de madeira tratados com solução de óleo de um lado e do outro lado da placa, madeira tratadas com o controle. Foram inseridos dez cupins na região central da placa e avaliou-se o número de insetos que se deslocaram para cada um dos lados durante os quinze minutos seguintes. $\mathrm{O}$ delineamento utilizado foi inteiramente casualizado com dez repetições por tratamento. $\mathrm{O}$ índice de repelência foi calculado como indicado por Vilallobos \& Robledo (1998) e os dados submetidos à análise de variância e as médias comparadas pelo teste de Tukey a $5 \%$ de probabilidade.

Paralelamente aos ensaios com os extratos e óleos, para todas as plantas testadas, foram feitos estudos visando à identificação da entomofauna associada às mesmas. Esse ensaio consistiu na observação dos insetos visitantes da planta, no tronco, nos ramos, folhas, flores e frutos no horário das 6:00 às 18:00 horas. Os insetos visitantes a cada 1/4 de hora foram coletados e identificados para fins de comparação de frequência desses organismos com as plantas testadas.

\section{RESULTADOS E/OU DISCUSSÃO}

De acordo com os resultados do ensaio, verificou-se que os óleos essenciais utilizados apresentaram potencial inseticida contra cupins do gênero Nasutitermes sp. Foram observadas diferenças estatísticas significativas entre as médias de mortalidade dos cupins nos tratamentos contendo os óleos em comparação ao tratamento controle (tween 1\%). Entretanto, não foram constatadas diferenças significativas nas mortalidades dos insetos, dentre as espécies L. thymoides (100\%) e L. lasiocalycina $(98,75 \%)$, sendo a espécie L. thymoides de efeito mais rápido, com mortalidade total nas primeiras 24 horas de exposição. As médias de mortalidade dos cupins em 24 horas diferiram das médias de 48 horas de exposição somente para o tratamento controle.

Para o extrato aquoso e metanólico, não foram constatados potencial inseticida contra cupins do gênero Nasutitermes sp, tanto nas primeiras 24 horas como nas 48 horas de exposição para todos os tratamentos. Em relação às diferentes diluições do óleo essencial da espécie Lippia thymoides, a concentração de $10 \mu 1 . \mathrm{ml}^{-1}$ apresentou média de mortalidade superior aos demais tratamentos, obtendo $77,19 \%$ de mortalidade dos insetos. Portanto é 
considerada como concentração letal (CL50) por ter apresentado capacidade de provocar $62,50 \%$ de mortalidade, na segunda hora de exposição (TL50), evidenciando assim sua rapidez de ação.

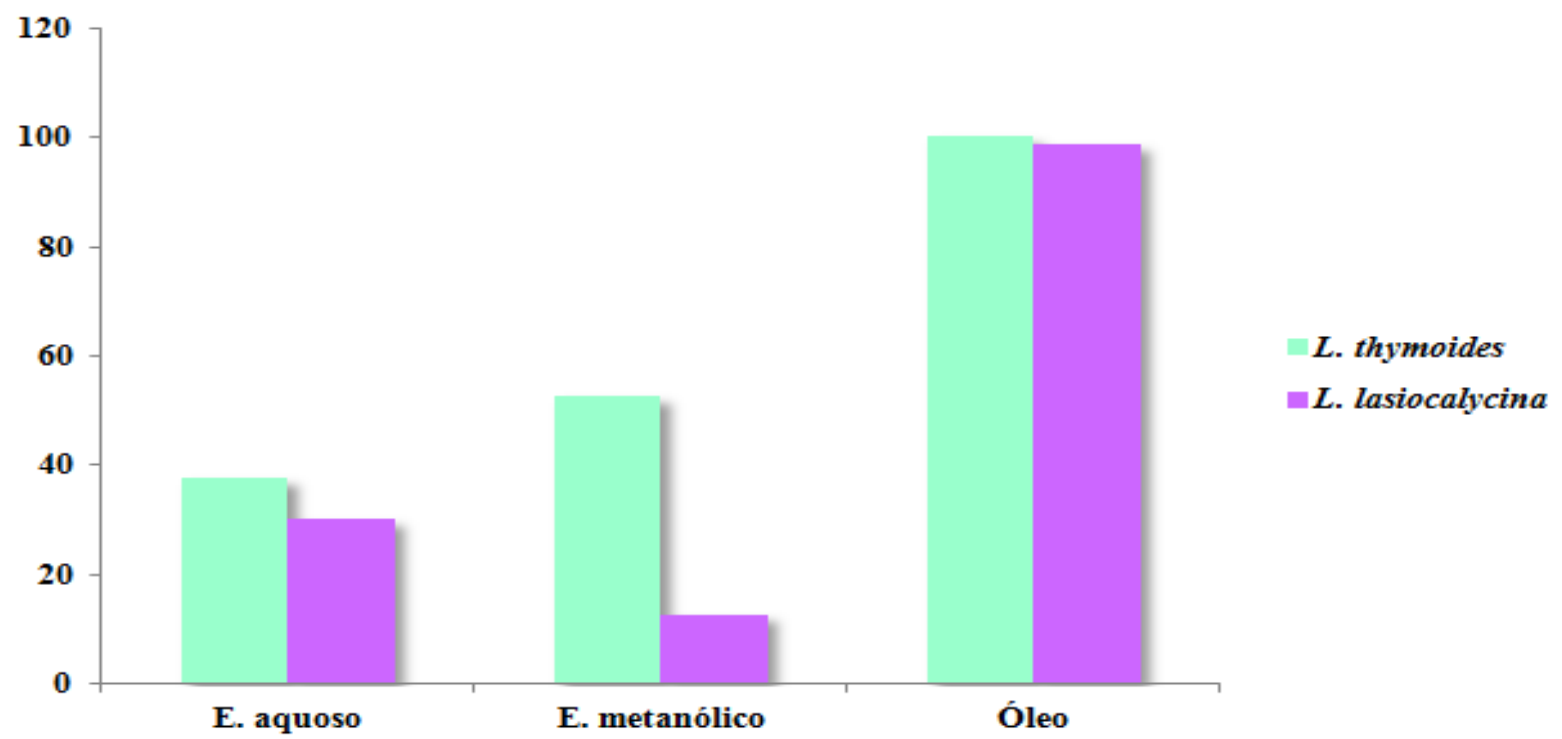

Figura 1: Comparação da mortalidade observada de cupins do gênero Nasutitermes sp, utilizando três diferentes produtos naturais das espécies L. thymoides e L. lasiocalycina.

Os resultados dos testes em aplicação tópica e superfície contaminada mostram que existem diferenças estatísticas entre o controle (tween 1\%) e o tratamento para ambos os métodos, sendo que no teste de exposição por aplicação tópica o tratamento promoveu uma média de $99 \%$ de mortalidade dos insetos. No teste em superfície contaminada foi observada alta eficiência da ação do produto com média de mortalidade de $100 \%$ dos insetos contra $62 \%$ do controle. Uma análise comparativa dos testes permite observar que, de forma geral, a aplicação em superfície contaminada mostra-se mais eficiente que a aplicação tópica, pois o mesmo promoveu $100 \%$ de mortalidade nas primeiras 24 horas de exposição, diferente do método de aplicação tópica em que a mortalidade de 100\% dos insetos ocorreu em 48 horas. O sucesso em superfície contaminada pode ser explicado pela capacidade de retenção do papel filtro, que proporcionou um contato mais prolongado dos insetos com as diluições do óleo.

No bioensaio de repelência, não foi obtido resultado positivo. As avaliações do mesmo, realizadas a 1,5, 10 e 15 minutos, resultaram em Índices de Repelência (IR\%) de 20,4; 17,5; 7,4 e 13,9, respectivamente. De acordo com Villalobos \& Robledo (1998), podem ser consideradas repelentes substâncias cujo índice está acima de 50\%, portanto, o presente estudo demonstrou que o óleo essencial de Lippia thymoides na concentração de $10 \mu \mathrm{l}^{-1}$ não é eficiente como repelente para cupins do gênero Nasutitermes sp.

Foram coletadas cinco ordens de insetos, Hymenoptera, Diptera, Hemiptera, Coleoptera e Lepidoptera, em cada uma das plantas observadas. Das 108 possibilidades de coleta de amostras da entomofauna associada à Lippia lasiocalycina e Lippia thymoides durante as nove datas, foi possível amostrar $77,8 \%$ na primeira e $86,1 \%$ na segunda espécie. A análise das ordens revela uma notável diferença de frequência de visitantes do grupo Hymenoptera em ambas as plantas, nas quais foram coletadas 38\% e 65,7\% amostras de Hymenoptera, respectivamente. 


\section{CONSIDERAÇÕES FINAIS}

De acordo com os dados obtidos, nas condições em que o experimento foi realizado, verificou-se que os óleos essenciais apresentaram potencial inseticida contra cupins do gênero Nasutitermes sp, enquanto que os extratos aquosos e metanólicos não demonstraram potencial. A concentração Letal (CL50) foi $10 \mu 1 . \mathrm{ml}^{-1}$, levando a mortalidade elevada dos insetos na segunda hora de exposição (TL50). O teste em superfície contaminada foi considerado como mais eficiente comparado à aplicação tópica, por ter apresentado índice de mortalidade superior. O óleo essencial da espécie L. thymoides não apresentou efeito repelente sobre os cupins. E foram coletadas cinco ordens de insetos, Hymenoptera, Diptera, Hemiptera, Coleoptera e Lepidoptera, havendo o predomínio da ordem Hymenoptera em ambas as espécies de Lippia estudadas.

\section{REFERÊNCIAS}

GIULIETTI, A. M., et al. Diagnóstico da vegetação nativa do bioma Caatinga. Biodiversidade da Caatinga: áreas e ações prioritárias para a conservação. p. 48-90. Ministério do Meio Ambiente, Brasília; 2004.

GOMES, S. V. F.; NOGUEIRA, P. C. L.; MORAES, V. R. S. Aspectos químicos e biológicos do gênero Lippia enfatizando Lippia gracilis Schauer. Eclética Química, v. 36, n. 1, p. 64-77, 2011.

OLIVEIRA, D. R, et al. Chemical and antimicrobial analyses of essential oil of Lippia origanoides H. B. K. Food Chemistry, v. 101, p. 236- 240, 2007.

QUEIROZ, L. P.; RAPINI, A.; GIULIETTI, A. M. Rumo ao Amplo Conhecimento da Biodiversidade do Semi-árido Brasileiro. Brasília: Ministério da Ciência e Tecnologia, 2006.

ROMAGNANO, L.F.T. di \& NAHUZ, M.A.R. Controle de cupins subterrâneos em ambientes construídos. Téchne 114: 48-53. 2006.

SANTOS, M. R. A. et al. Atividade inseticida do extrato das folhas de Piper hispidum (Piperaceae) sobre a broca-do-café (Hypothenemus hampei). Revista Brasil. Bot., V.33, n.2, p.319-324, abr.-jun. 2010.

VILLALOBOS, M. J. P. \& ROBLEDO, A. Screening for anti-insect activity in Mediterranean plants. Industrial Crops and Products 8:183-194, 1998. 